\title{
EL CULTO DE LOS NIÑOS
}

D avid $A$ smat C hávez, Lic.

Facultad de Teología

U niversidad Peruana U nión

david_asmat2003@hotmail.com

Fecha de recepción: M ayo 2012

Fecha de aceptación y versión final: Julio 2012

Resumen U no de los deberes a los que más se le ha de brindar nuestra atención, son los cultos dirigidos a nuestros niños. La orientación de las Sagradas E scrituras y del espíritu de profecía debe ser nuestro mayor fundamento y aval. La formación de su carácter y el amor que pueda cultivarse en sus corazones hacia Dios, dependerá de la manera cómo compartamos nuestros momentos de devoción en su más tierna etapa. En este sentido considerar la manera en cómo nos familiaricemos con el desarrollo de nuestros niños es importante. Esto, nos permitirá desarrollar cultos que no sean muy "fríos o secos", sino que sean cultos donde ellos disfruten pasar tiempo con nosotros y Dios.

Palabras clave: $\mathrm{N}$ iños, culto, espiritualidad, familia. 
Por la noche y por la mañana uníos con vuestros hijos en el culto a Dios, leyendo su Palabra y cantando sus alabanzas. Enseñadles a repetir la ley de D ios... M oisés instruyó a los israelitas a ponerles música... En los años subsiguientes retenían en su mente las palabras de la ley que aprendieran durante la niñez.

Elena $G$. de W hite El evangelismo, 365

\section{Introducción}

El presente artículo tiene como propósito un breve repaso de los consejos de las Sagradas Escrituras y del Espíritu de Profecía en relación al culto de los niños. También se considerará la manera cómo aprenden según su edad. Así, más que solo brindar un bosquejo o programa de un culto familiar, nuestra intención principal es considerar tanto la forma en la que este se debería desarrollar, así como la intención en la praxis del culto familiar para los niños.

\section{La B iblia y nuestra res ponsabilidad del culto familiar}

Para muchos resulta familiar el texto que dice: "Instruye al niño en su camino, y aun cuando fuere viejo no se apartará de él" (Pr 22:6). Este texto no sólo llama la atención propiamente a la importancia que se le debe dar a la educación de los hijos, sino también al hecho de que la niñez es una etapa crítica. La expresión na'ar, "niño o adolescente", implica la etapa crucial de la formación de los hijos. ${ }^{1}$ Así también, la expresión usada en el texto de forma imperante hanak, traducida comúnmente como "instruye", puede entenderse como "formar una costumbre 0 entrenar". Esto implicaría la formación de un hábito saludable en la vida del niño que pueda acompañarle el resto de sus días. ${ }^{2}$

Ahora bien, no resulta solo el hecho de hacerlo, pues en las cuatro veces que aparece el verbo hanak, posee un sentido de dedicación o entrega de algo único y nuevo a Dios. ${ }^{3}$ Esto nos debe mover a considerar la men-

1 C. F. Keil y F. Delitzsch, Commentary on the Old Testament (Peabody, MA: Hendrickson, 2002), 222. D. Carro, J. T. Poe y R. O. Zorzoli, eds., Comentario bíblico mundo hispano ProverbiosCantares (El Paso, TX: Editorial Mundo Hispano, 1993), 219.

2 Luis Alonso Shokel, “\%(低, Diccionario Hebreo Español (Madrid: Editorial Trota, 1994), 266.

3 Los textos que se muestran como referencias son: Dt 20:5; 1 R 8:63; 2 Cr 7:5 y $\operatorname{Pr} 22: 6$. 
te del niño como un vaso de cristal nuevo y vacío que deberá comenzar a ser llenado de las lecciones de amor que D ios nos legó. Y esto en cada culto matutino y vespertino.

En esa misma dirección y mucho tiempo antes, Moisés al dar su discurso al pueblo de Israel exhortó a la observancia de los preceptos divinos haciendo una referencia muy enfática al valor de la instrucción familiar, la cual debe ser asidua, fervorosa y frecuente ${ }^{4}$ pues solo así se conservaría al pueblo del error y la apostasía. Lo impresionante aquí es que el grupo receptor 142 son sus hijos, pues ellos eran el presente y serían el futuro de Israel.

Deuteronomio 6:4-9, contiene la shema y el énfasis mosaico de la forma de instrucción padre hijo dentro del pueblo hebreo. De esta manera D euteronomio 6 pasó a ser el núcleo de la fe hebrea. ${ }^{5}$ Así también, éste debe

4 R. Jamieson, A. R. Fausset, y D. Brown, Comentario exegético y explicativo de la Biblia: El Antiguo Testamento (El Paso, TX: Casa Bautista de Publicaciones, 2003), 1:159.

5 Carro, Poe y Zorzoli, Comentario bíblico mundo hispano Proverbios-Cantares, 219. verse contemplado como un ciclo de aprendizaje que no sólo descansa en lo cognoscitivo sino que abarca el área práctica durante todo el día, siendo asociadas con un estilo de vida y no sólo con un formalismo. Aunque el pueblo hebreo comprendió mal esta práctica, y usaron los telifin (porciones de la Escritura colocadas en sus frentes), lo cierto es que Moisés expreso en un sentido figurado la manera cómo debía mantenerse el amor a Dios en sus corazones y en sus hogares. ${ }^{7}$ El Cuadro 1 ilustra el proceso enseñanza -aprendizaje descrito en Dt 6:6-9:

Una consideración adicional e importante debe hacerse en relación a Proverbios 31. Este pasaje insta a que dentro del hogar no existan incongruencias entre lo que se dice y se hace. Recuerde que esa es la razón más fuerte por la cual mayormente los niños hacen todo lo contrario de lo que nosotros procuramos enseñarles. En este capítulo vemos a una madre

6 Jamieson, Fausset y Brown, Comentario exegético y explicativo de la Biblia, 1:159-160.

7 M. Henry, Comentario de la Biblia Matthew Henry (Miami: Editorial Unilit, 2003), 167. 


\section{Cuadro 1. Proceso de enseñanza - aprendizaje descrito en Dt 6: 6-9}

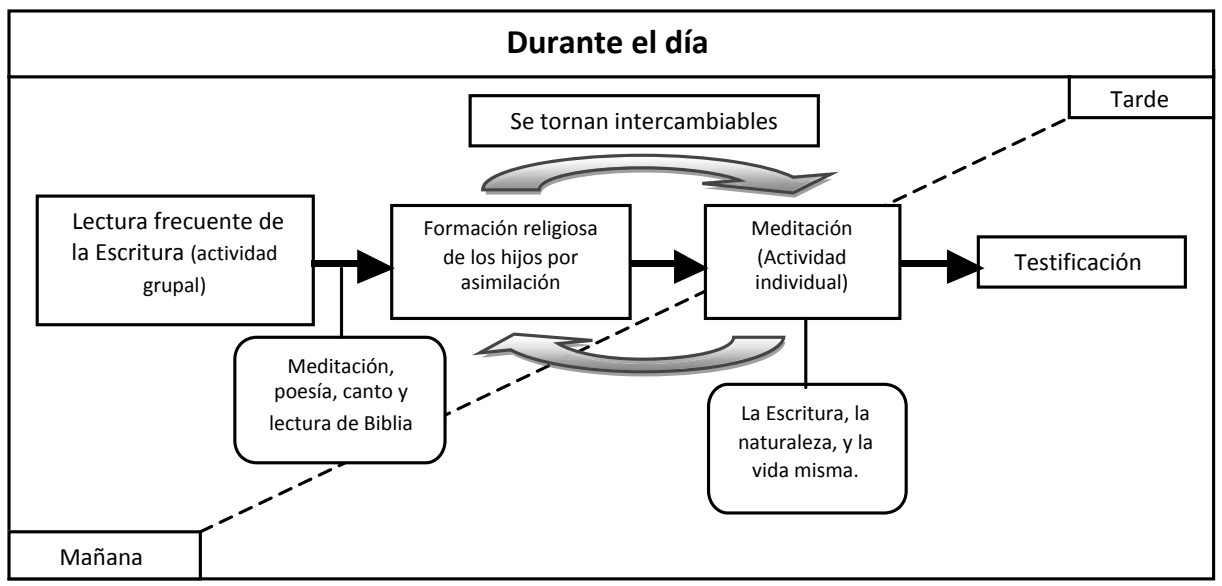

instando a su hijo a andar en los caminos correctos, caminos en los que su padre lo ha venido instruyendo.

\section{Al considerar lo expuesto} hasta aquí, se nota la tremenda oportunidad y responsabilidad que Dios ha dado a los padres. Por ello debemos escribir estos principios a lo largo del día y mediante cada culto matutino y vespertino, de tal forma que queden grabados en las tablas del corazón de los niños (Pr 3:3). Por ello no debe olvidarse que los padres deben ser grandes maestros motivadores $(\mathrm{Pr}$ 4:1-7). "Pues herencia de Jehová son los hijos" (Sal 127:3).

\section{El valor del culto familiar y el Espíritu de Profecía}

Respecto al culto familiar Elena G. de W hite, ha mostrado enfoques que pueden causarnos más que solo una reflexión. Algunos podemos creer que nuestros niños no están listos para comprender lo que implica el amor a Dios. Sin embargo ella señala: "Tan pronto como un niño puede amar a su madre y confiar en ella puede amar a Jesús y confiar en él". ${ }^{8}$ C abe resaltar que esta descripción del acercamiento de los niños a C risto no corresponde a un acto

8 Elena G. White, Conducción del niño (Buenos Aires: Asociación Casa Editora Sudamericana, 2008), 460. 
simplemente cognoscitivo sino práctico que descansa sobre la base del ejemplo. En la página 493 del mismo libro, Elena G . de W hite pone un énfasis en el cuidado entre lo que se suele pedir de los niños en los cultos y el ejemplo que podemos darles.

Ella señala además que debemos cuidar que nuestro trato no sea severo y frío en el desarrollo de culto. En este sentido, no sólo expone la relevancia de la práctica del culto y la oración, sino que advierte sobre una probable práctica desabrida y monótona que es señalada como la que contribuye al incremento 144 de inmoralidad y pérdida de valores cristianos:

...en esta época tan peligrosa, algunos de los que se llaman cristianos no celebran el culto de familia. No honran a D ios en su casa, ni enseñan a sus hijos a amarlo y temerlo... No están en comunión con él. Su piedad no es más que una forma sin fuerza. ${ }^{9}$

En un mundo donde somos presa de las circunstancias, Elena G. de W hite exhorta a que el culto familiar no sea presa de las circunstancias.

9 Ibíd., 490.
$N$ o habéis de orar ocasionalmente y descuidar la oración en un día de mucho trabajo. Al hacer esto inducís a vuestros hijos a considerar la oración como algo no importante".$^{10}$

La declaración de Elena $\mathrm{G}$. de W hite, recae sobre la ligereza mostrada durante el culto familiar, la posible prisa para realizarlo o la ausencia provocada por alguna "obligación urgente". El padre en primer lugar debe considerar su rol de sacerdote del hogar $y$, en la medida en que asuma responsablemente y dirija los cultos matutinos y vespertinos, estos deberán ser bre ves, animosos, interesantes y no secos y tediosos." Un adecuado desarrollo del culto familiar despertará o fortalecerá el amor por el estudio de la Biblia.

Un modelo tradicional de cómo se puede desarrollar el culto familiar aparece en Conducción del niño:

Los jefes de familia debieran ocuparse especialmente de que la hora del culto sea sumamente interesante [preparación]. D edicándole algo de atención y cuidadosa

10 Ibíd., 493.

11 Ibíd., 493. 
preparación, cuando nos presentamos ante la presencia de Dios, el culto familiar puede ser agradabley estará lleno de resultados que únicamente revelará la eternidad [preparación]. Elija el padre una porción de las E scrituras que sea interesante y fácil de entender; se rán suficientes unos pocos versículos para dar una lección que pueda ser estudiada y practicada durante el día [intención reflexiva]. Se pueden hacer algunas preguntas [desarrollo]. Pueden presentarse a manera de ilustración unas pocas, serias e interesantes observaciones, cortas y al punto [metodología del desarrollo]. Por lo menos debieran cantarse unas pocas estrofas de un himno animado, y la oración debe elevarse corta y al punto [cierre]. El que dirige en oración no debiera orar por todas las cosas, sino que debiera expresar sus necesidades con palabras sencillas y su alabanza a D ios con gratitud [cierre].12

Eso no debe ser una excepción los sábados. Los niños de ben participar los sábados de un culto especial, muy aparte del culto regular. ${ }^{13}$

12 Ibíd., 494. Los corchetes son nuestros.

13 Elena G. de Whie, Servicio cristiano y eficaz (Buenos Aires: Asociación Casa Editora Sudamericana), 260.

\section{¿Cómo aprenden los ni- nos?}

Me ha parecido importante considerar en esta sección la manera en cómo los niños aprenden, pues creo que esto no sólo atañe a la enseñanza dentro de las escuelas, sino que también debe tomarse en cuenta en cada hogar. Los padres somos más que padres, somos maestros por naturaleza y nuestros actos siempre enseñan algo. Por ello debemos tener presente y de manera urgente, que la niñez de nuestros hijos es la oportunidad para formar verdaderos hijos de Dios 0 de lo contrario, simplemente cristianos nominales.

Hemos de recordar que un niño aprende más por el método de prueba y error, por la experiencia, por medio del placer de experimentar, por la interacción social y la sugerencia, antes que por la coerción. ${ }^{14}$

La niñez se caracteriza básicamente por las siguientes etapas: la primera de 0 a 4 años, la segunda de 5 a 7 y la tercera etapa de 8 a 11 años (etapa preadolescente), etapas en las que

14 David Wood, Cómo piensan y aprenden los niños (Coyoacán, México: Siglo XXI Editores, 2000), 20, 21. 
el niño manifiesta características particulares en su aprendizaje. ${ }^{15}$

Durante la primera etapa la función importante es la manipulación física, esto quiere decir que el niño en esta edad, logrará asimilar las lecciones y enseñanzas mediante la interacción con objetos más que sólo por el oír.

Durante la segunda etapa el énfasis se torna más reflexivo. Aquí la expresión " ¿por qué...?" estará a flor de labios, y la persona que está resuelta a responder, debe dar respuestas precisas a preguntas precisas. En esta etapa el aspecto reflexivo/ práctico deuna lección o historia enseñada será vital.

Durante la tercera etapa el pensamiento se hace cada vez más abstracto y dependiente de lo verbal. Estará más apto para aprender a través de historias un poco más largas.

Sin embargo, hemos de considerar que las características de estas tres etapas conciben un de sarrollo paralelo, pues a medida que adquieren una nueva mane ra de aprender, la habilidad de aprendizaje anterior se ve asociada tambien. ${ }^{16}$
0-4 años
manipulación física y actos representativos
5-7 años
mós rếexivo
8-11 años
más abstracto y dependiente de lo verbal

15 María Eugenia Mansilla A., "Etapas del desarrollo humano", Revista de Investigación en Psicología 3, No.2 (2000), 108; Grace J. Craig, Desarrollo psicológico (México: Pearson Educación, 2001), 4-6.
16 Una referencia más amplia respecto al aprendizaje cognoscitivo de Bruner lo encontrará en J. S. Bruner, Toward a Theory of Instruction (Cambridge MA: Harvard, 1966). Véase también David R. Shaffer, Psicología del desarrollo, infancia y adolescencia (Seneca, México: International Thomson Editores, 2000), 228-266. 
U na de las consideraciones que se requiere para desarrollar el culto es: ¿Cuánto tiempo ha de emplearse? El culto puede durar todo el tiempo que se desee, siempre y cuando el niño disfrute esos instantes. ${ }^{17} \mathrm{En}$ tal sentido habría que considerar que el tiempo debería está en función a la capacidad de atención del menor, puesto que cada niño es distinto. ${ }^{18}$

El siguiente cuadro procura mostrar, según la edad, elementos que puedan ayudarlo a tener una idea de lo que uno debeconsiderar al momento de poner en práctica un culto familiar:

\section{Conclusión}

No esperamos que todo lo mencionado aquí sea suficiente, hay mucho más que investigar y hacer. Recuerde que el culto de los niños debe ser de los niños, y que cada historia debe estar adaptada a su edad. Recuerde también que para que él disfrute estos momentos, debe verlo a usted disfrutándolos. Por último recuerde que su ejemplo determinará la eficacia del culto y la formación de los valores cristianos del niño.

17 Jhon Trent, Rick Osborne y Kurt Bruner, Guía para el crecimiento espiritual de sus hijos (El Paso, TX: Editorial Mundo Hispano, 2003), 179.

18 B. A. Barnes, El sentido común en la educación de los más pequeños (Madrid: Ediciones Narcea, 2005), 126. 


\begin{tabular}{|c|c|}
\hline Edad & Como aprenden \\
\hline $0-4$ años $^{1}$ & $\begin{array}{l}\text { 0-1 año: Debe recordar que el recién nacido está en una etapa de } \\
\text { exploración, y que mientras el no interactúe/toque los objetos no } \\
\text { aprenderá (él debe tocar y chupar para aprender). } \\
\mathbf{2} \text { años Use juguetes que representen la historia que quiere enseñar. } \\
\text { U sted puede valerse de fotos de imágenes que le puedan ser familiares } \\
\text { para desarrollar una lección para ellos. U se manuales, muy gráficos. Debe } \\
\text { ayudarle a ordenar las historias en su mente. Él posee las imágenes, usted } \\
\text { debe ayudarle a organizarlas. } \\
\text { 3-4 años: A quí usted puede emplear cantos que generen psicomotricidad; } \\
\text { use el dibujo, también usted puede representar a personajes (disfrácese), } \\
\text { haga lo mismo con él o ella. Si él quiere ser David y quiere que usted sea } \\
\text { G oliat, ihágalo! él no lo olvidará nunca. A simismo, usted puede empl ear } \\
\text { fracciones de textos al usivos, que él pueda gravar en su mente. Sobre } \\
\text { todo permítale escoger. Esto es muy importante pues más que en } \\
\text { cualquier otra etapa el vínculo de afecto será mucho mayor con su } \\
\text { persona. }\end{array}$ \\
\hline 5-7 años ${ }^{2}$ & $\begin{array}{l}\text { En esta edad están listos para historias más largas y más detalladas, } \\
\text { recuerde que gozan de gran imaginación. En esta edad usted puede usar, } \\
\text { adivinanzas, historias que desarrollen su imaginación ( N aamán, B al aam } \\
\text { y la burra que habló, J onás y el gran pez, etc.). U se también } \\
\text { rompecabezas de historias bíblicas e ínstelos a dibujar y colorear. Si entre } \\
\text { los tres y cuatro usted podía usar actividades que generen movimiento } \\
\text { aquí su psicomotricidad es mucho mayor. A quí el proceso de enseñanza } \\
\text { debe ser más dinámico y atractivo. }\end{array}$ \\
\hline 8-11 años 3 & $\begin{array}{l}\text { Podremos notar un creciente desarrollo de las capacidades físicas, una } \\
\text { liberación de la influencia del hogar por una mayor influencia de los } \\
\text { compañeros, así como el aumento de la capacidad de pensamiento lógico. } \\
\text { A quí podría emplear al gunas cosas como: cuál será el lema de hoy, o el } \\
\text { uso de analogías, permítales dirigir el culto de casa (si ellos desean invitar } \\
\text { a un amigo(a) no lo impida, sea amigo de sus amigos). Hablen acerca del } \\
\text { valor de la amistad y los afectos al sexo opuesto. Fomente el valor de la } \\
\text { música cristiana y oriéntelo en relación al el estilo de vida cristiano. } \\
\text { Programe salidas a lugares especiales como: orfanatos, hospitales y } \\
\text { asilos, procurando fortalecer los valores sembrados en ellos en los años } \\
\text { anteriores. }\end{array}$ \\
\hline
\end{tabular}

1. E. Goldshemied y S. Jackson, La educación Infantil de 0 a 3 años (Madrid: Ediciones Morata, 2007), 119-145. Dennis Coon, Fundamentos de Psicología (México: International Thomson Editores, 2005), 314. Irma María Zúñiga León, Principios y técnicas para la elaboración de materiales didácticos para el niño de 0 a 6 años (San José, Costa Rica: Editorial Universidad Estatal a Distancia, 1998), 94, 233.

2. Eulalia Basedas, Teresa Hugeet y Isabel Sole, Aprender y enseñar en educación infantil (Barcelona: Editorial Graó, 2006) 67, 68.

3. Esta etapa es una de las más complejas pues es donde el niño enfrentará una mayor presión social a optar por actitudes y valores que podrán afectar de manera directa las enseñanzas en casa. Aunque esto puede parecer poco significativo en relación al culto familiar, es vital pues en esta edad ellos tienden a buscar una mayor identificación social con grupos de su misma edad. Donna J. Habenicht, Diez valores cristianos que todo niño debería conocer (Buenos Aires: Asociación Casa Editora Sudamericana, 2000), 16, 45. 